\title{
PANORAMA HISTÓRICO E ANALÍTICO DOS ESTUDOS EM CIÊNCIA, TECNOLOGIA E SOCIEDADE
}

\author{
HISTORICAL OVERVIEW AND ANALYTICAL STUDIES IN SCIENCE, \\ TECHNOLOGY AND SOCIETY
}

Adriano Premebida ${ }^{1}$

Resenha do livro de MATTEDI, Marcos. Sociologia e Conhecimento: introdução à abordagem sociológica do problema do conhecimento. Chapecó, SC: Editora Argos, 2006, 218 páginas.

Este livro de Marcos Mattedi, fruto da sua experiência docente com a disciplina de Sociologia do Conhecimento e de estágio pós-doutoral no Centre de Sociologie de l'Innovation da École des Mines, de Paris, embora seja uma introdução aos estudos sociológicos sobre o problema do conhecimento, merece uma atenta leitura, mesmo por parte dos leitores já habituados às discussões deste vasto campo temático. Apesar de, por convenção, o livro estar situado em um espaço ligado a abordagens sociológicas da relação entre sociedade e conhecimento, é um tanto difícil separar os resultados das pesquisas atuais que visam ao "social" no conhecimento científico, em campos disciplinares, tais como antropologia, crítica literária, estudos feministas, história, filosofia e sociologia. Geralmente tais estudos são unificados pela denominação Science Studies, ou ainda, Estudos em Ciência, Tecnologia e Sociedade (CTS). Não obstante, esta discussão sobre qual espaço disciplinar ou orientação metodológica cada estudo apresenta não encerra, ainda, um embaraço ou um problema no Brasil. As discussões sobre o problema do conhecimento científico ${ }^{2}$ de um ponto de vista social ou sociológico são fragmentárias e pouco estabelecidas por aqui ${ }^{3}$, com exceção, talvez, das pesquisas sobre o caráter institucional da ciência brasileira:

\footnotetext{
1 Pesquisador e Diretor Técnico-científico da Fundação Amazônica de Defesa da Biosfera - DITEC/FDB, email para contato: premebida@fdb.org.br

2 Tendo em vista o importante espaço ocupado pela ciência nas sociedades a partir do século XIX, a sociologia do conhecimento tende naturalmente a considerar a ciência como foco prioritário de análise.

3 Embora uma diversidade de modelos teóricos e metodológicos surja no final da década de 1970 com a descensão do modelo mertoniano, apenas agora o número de pesquisas no Brasil toma forma mais consistente. Basta ver o número crescente de dissertações e teses sobre o tema, com abordagens contemporâneas.
} 
em termos de sua organização, da comunicação ou circulação de seus resultados, dos sistemas de credenciamento e valoração.

A organização do livro é feita de acordo com o critério do agrupamento cronológico ou histórico dos autores, e respectivas teorias, na formação do que se considera a sociologia do conhecimento e, mais recentemente, a sociologia do conhecimento científico. Como não são poucos, e tratar todos não é tarefa simples, Mattedi apresenta, dentro do possível e do arbitrário ${ }^{4}$, os principais autores ligados a esta temática. Em termos de forma, a qualidade do livro é notável, embora nesta primeira edição alguns erros se apresentem, como vogais trocadas ou palavras com falta de letras. Nada que comprometa a obra, contudo.

Para fins de sistematização, dividi o livro em cinco partes. Na introdução, o que considero a primeira parte, estão as principais visões e divisões das investigações filosóficas sobre a problemática do conhecimento, sua origem, suas possibilidades e limites. Ainda hoje são estas perspectivas, de fundo epistemológico, que orientam e influenciam as preocupações sociológicas sobre os processos de obtenção, justificação e difusão do conhecimento. Esta primeira parte fundamenta-se ou nos argumentos e críticas decorrentes dos postulados teóricos do Círculo de Viena, das formas válidas do raciocínio científico, se condicionado por fatores internos, próprios de uma lógica da justificação de sistemas abstratos que equilibram a equivalência entre teorias e verificação empírica; ou nas análises empreendidas de acordo com fatores "externalistas", baseados nas experiências históricas de como a atividade científica resolveu socialmente suas lacunas teóricas e experimentais ${ }^{5}$.

Temos, então, um apanhado de autores e seus pressupostos epistemológicos expostos de acordo com suas divergências entre posições internalistas (Auguste Comte, Círculo de Viena e Karl Popper) e externalistas (Thomas Kuhn, Imre Lakatos e Paul Feyerabend) sobre o conhecimento científico. As questões relacionadas aos procedimentos metodológicos da ciência e seus critérios de racionalidade e verdade, embora não cheguem a ser analisados detidamente, são apropriadamente situadas: o falsificacionismo popperiano; o "anarquismo" metodológico de Feyerabend; as noções de ciência normal e revolução científica de Kuhn; a estrutura lógica de análise dos enunciados científicos do Empirismo Lógico (Círculo de Viena); e as posições sobre as rupturas da história da ciência e seus procedimentos cognitivos de retificação e constituição do real, através da superação de representações da realidade filtradas pelo senso comum (tradição epistemológica francesa de Alexandre Koyré, Gaston Bachelard e Georges Canguilhem).

É a partir do acúmulo de discussões entre estas tradições epistemológicas que Mattedi inicia o exame, na segunda parte do livro, dos precursores das discussões consideradas propriamente sociológicas na caracterização e constituição do conhecimento: Karl Marx, Émile Durkheim e Max Weber. Após considerar a contribuição destes autores, analisa, em uma terceira parte, os "institucionalizadores" da abordagem sociológica do problema do conhecimento (científico): Max Scheler, Karl Mannheim e Robert Merton. Em uma quarta fase aborda Jürgen Habermas, Michel Foucault e Pierre Bourdieu que, não obstante as diferenças, têm em comum a posição crítica sobre as relações entre conhecimento científico, poder, interesses e a dinâmica do campo científico, ou seja, os acúmulos e a circulação de capitais simbólicos bem como as relações entre o empreendimento científico com outras práticas culturais.

\footnotetext{
4 Sempre existe uma brecha para argumentar que tal autor não é pertinente ao tema, que este e aquele ficaram de fora, ou que tal capítulo mereceria maior alcance. Mas, faz falta, neste momento, um livro com as discussões dos estudos sobre ciência e tecnologia posteriores à década de 1980. Há muito debate, senão "guerras científicas", a partir daí. Talvez uma obra com esta perspectiva despertasse maior interesse sobre estes estudos no Brasil.

5 A compreensão da ciência não a partir de sua "reflexão lógica", mas de sua prática.
} 
Na quinta parte do livro, antes de o autor alinhavar uma espécie de resumo propositivo do plano da obra, temos estudos mais recentes e precisos, em termos metodológicos e empíricos, derivados do profundo debate estabelecido com as discussões clássicas da sociologia e filosofia do conhecimento e as variadas perspectivas unificadas sob a denominação Estudos Sociais da Ciência e Tecnologia e/ou Science Studies. Este encontro de estudos históricos, antropológicos, sociológicos e filosóficos enriquece a compreensão do papel do contexto social ${ }^{6}$, ou laboratorial, na constituição do conhecimento tecnocientífico, desde a perspectiva teórico-metodológica das três "Escolas" mais conhecidas no momento: a Escola de Edimburgo, Escola de Bath e Escola de Paris, as quais agora sintetizo.

A Escola de Edimburgo e/ou o Programa Forte em Sociologia do Conhecimento: centrada em estudos de caráter macrossociológico, com o objetivo de analisar os condicionantes do conteúdo do conhecimento científico. O Programa Forte propõe uma sociologia não mais voltada ao estudo das instituições e da comunidade científica, como na tradição mertoniana, mas do próprio conhecimento científico.

A Escola de Bath e/ou o Programa Empírico do Relativismo e Construção Social da Tecnologia: de perspectiva microssociológica, utiliza-se de estudos empíricos sobre controvérsias e negociações científicas para compreender como problemas sociotécnicos (a caixa-preta) tomam forma, se recrudescem e se estabilizam.

A Escola de Paris e/ou a Sociologia da Tradução: talvez a mais conhecida no Brasil em função das traduções de alguns livros de Bruno Latour, pauta-se, principalmente, pelas etnografias de laboratório (a descrição dos cientistas em suas rotinas), pelas vinculações dos cientistas com as questões técnicas e não-técnicas de variadas ordens, como também pelas relações entre o aparato material de um laboratório e seus sistemas de inscrição de dados em textos, programas computacionais, tabelas e gráficos.

Ao fim do livro chega-se à conclusão de que o conhecimento científico é um empreendimento heterogêneo e, mais que um conjunto de teorias, é uma prática, ou seja, o experimento laboratorial é essencial na produção do conhecimento científico. Fica, assim, na integração entre experimentos e teorias, um amplo espaço de estudos sobre as relações e implicações sociais da ciência e tecnologia. Ambas, pelas mãos dos cientistas, estão a todo o momento articulando interesses sociais com os objetivos estritos da pesquisa, apesar dos esforços, no nível da argumentação e da retórica ${ }^{7}$, de mostrarem-se como neutras e desinteressadas. Isso, todavia, não retira a força explicativa do conhecimento científico, mas esclarece o quanto o social é um elemento de legitimação da ciência e da tecnologia e mesmo um processo imanente aos seus efeitos de neutralidade e sofisticação teórica, no âmbito da justificação da relação experimento-teoria. Os processos de produção de conteúdo cognitivo não são podados pelos interesses e influências sociais diversas. A questão é compreender, justamente, pelo leque de opções teórico-metodológicas da sociologia do conhecimento científico e tecnológico, como estas dimensões sociais diversas sustentam este mundo humano tecnificado.

\footnotetext{
6 Bruno Latour problematiza ainda mais a questão do contexto social. Ele é enfático em dizer que a atividade científica vista microscopicamente nos mostra o quão problemática é qualquer distinção entre o que é interno e externo, entre o que é social e o que é científico. Para ele não é necessário buscar o contexto social a fim de se entender a construção do conhecimento científico, basta analisar os constantes processos de tradução entre naturezas (de uma rocha para um texto ou outra inscrição qualquer) que há no laboratório ou nos espaços de estudos experimentais e coleta de dados dos cientistas.

7 Como se constrói pela linguagem o caráter natural das ciências ditas naturais?
} 